\title{
Mandatory Pre-Employment Medical Examination-The Practice and the Law: Is It Justifiable?
}

\author{
Adomako-Kwakye Chris ${ }^{1}$, Alexander Oti Acheampong2* ${ }^{*}$ Akwasi Antwi-Kusi³, \\ Emmanuel Ameyaw ${ }^{3}$
}

${ }^{1}$ Commercial Law Department, Faculty of Law, Kwame Nkrumah University of Science and Technology, Kumasi, Ghana

${ }^{2}$ Oral and Maxillofacial Surgery Department, Dental School, Kwame Nkrumah University of Science and Technology, Kumasi, Ghana

${ }^{3}$ School of Medical Sciences, Kwame Nkrumah University of Science and Technology, Kumasi, Ghana

Email: *aotiacheampong@yahoo.com

How to cite this paper: Chris, A.-K., Acheampong, A. O., Antwi-Kusi, A., \& Ameyaw, E. (2017). Mandatory Pre-Employment Medical Examination-The Practice and the Law: Is It Justifiable? Beijing Law Review, 8, 1-9.

https://doi.org/10.4236/blr.2017.81001

Received: November 9, 2016

Accepted: February 19, 2017

Published: February 22, 2017

Copyright $\odot 2017$ by authors and Scientific Research Publishing Inc. This work is licensed under the Creative Commons Attribution International License (CC BY 4.0).

http://creativecommons.org/licenses/by/4.0/

\begin{abstract}
"An employee shall not in respect of any person seeking employment, or of persons already in his employment; discriminate against the person on grounds of gender, race, colour, ethnic origin, creed, social or economic status, disability or politics" (Section 14(e) of the Labour Act 651). The aim of this study is to evaluate the process of pre-employment medical report examinations, the law and the practice-in some public institutions in Kumasi. This study was conducted in two major public institutions in the Kumasi metropolis. The identities of respondents will remain confidential so as to maintain anonymity. Three groups of respondents were used in the study (Group 1: Employees who were employed within the past 5 years. Group 2: Eight medical doctors who have been mandated to conduct and write medical reports of prospective employees. Group 3: Ten senior human resource staff members of the two aforementioned public institutions). Each group was asked specific questions related to the process of medical examinations and the laws of employment. Responses were analyzed and reported descriptively using SPSSII. All respondents from Group 1 were asked to submit to a medical examination commencing work. Sixty-five (65\%) percent of respondents in Group 2 indicated that they were unaware of the job description of a prospective employee at the time of examination. All members in Group 3 indicated that the medical examination results of applicants are kept on their personal files, which are accessible to other human resource personnel. Based on the above section of the Labour Act of 2003, it is our assertion that there is no legal basis for the mandatory request of medical examination reports of prospective employees. Again, the medical reports do not always take into consid-
\end{abstract}


eration the job description of the prospective employee. Therefore, reliance on a medical report to determine the fitness of a prospective employee for a particular job is not based on fair evaluation and thus not justifiable for the institutions studied.

\section{Keywords}

Pre-Employment, Medical Examination, Practice, Law

\section{Introduction}

Every employer would want to maximize their return on investment including the health of their workforce. To this end, employers oftentimes seek to obtain a medical report on the prospective employee. Assessment of fitness for work is defined as the evaluation of a worker's capacity to work without risk to their own or others' health and safety (Cox et al., 2009). The request for a medical examination serves several purposes for the benefit of the employer and the employee. A pre-employment medical check has thus become mandatory for most employers especially Ghana.

It is done to ensure that the prospective employee has no "grave medical condition" and that the employee is "physically and mentally" fit for the position offered (Cox et al., 2009).

In some other cases, the demands of the work require that the prospective employee should meet certain minimum required medical standards in order to qualify for the appointment ((Labor Act, 2003b), Act 651, 2003, section 59(1)). Depending upon the contents of the medical report, a decision may be taken either to provide an offer to the prospective employee or decline further consideration. Sometimes, the employee is informed in the appointment letter that their employment will be confirmed subject to the ascertainment of satisfactory medical condition.

These findings have led to the following research question: Is it necessary to mandate pre-employment medical examinations for specified jobs in Ghana? The Employment Equity Act, 55 of 1998 (Employment Equity Act, 1998) prevents medical screening of a prospective employee save where the work has some "inherent requirements" and the medical screening is needed to ascertain whether the person is fit or not. The relevant provision is as follows:

"Medical testing of an employee is prohibited, unless-

a) Legislation permits or requires the testing or

b) It is justifiable in the light of medical facts, employment conditions, social policy, the fair distribution of employee benefits or the inherent requirements of a job."

Ghana does not have enough laws on this subject under discussion. Our courts are not bound by laws in the United States of America but can have persuasive effect. In this regard, we want to examine laws in other jurisdictions. California's Fair Housing and Employment Act (FEHA) (California Gov't Code 
$12940(\mathrm{e}-\mathrm{F}))$ prohibits employers from requiring job applicants to take a medical or psychological examination. The FEHA also prohibits employers from inquiring about any mental or physical disability or medical condition. However, the employer may ask about an applicant's ability to perform any job-related functions. Also, if an applicant requests a reasonable accommodation on the job, the employer may respond by asking why it is necessary. For example, an applicant with a disability that prevents using a computer keyboard may ask for voicerecognition software and the employer is permitted to ask the reason for the demand. After extending an offer, the employer may ask the applicant to have a pre-employment medical examination or laboratory test, as long as it relates specifically to the requirements of the job (California Gov't Code 12940(e-F)). There are no statutory guidelines in California Law which addresses employee drug testing. Such law can however be created based on court decisions. In general, courts have required employers to have a "particular suspicion" that an employee's ability to perform their job is impaired by drugs before requiring a drug test.

Both random and mandatory drug testing of employees are allowed whose jobs are safety sensitive. Examples of safety-sensitive jobs include: police officers and firefighters, public transit workers involved in driving or maintenance, as well as nurses. Random drug testing, however, violates the privacy of an employee whose work raises no safety issues that would require a random drug test (Luck v. Southern Pacific Transportation, 1990).

The objective of conducting pre-employment medical screening is deemed to ensure that a person is fit to perform a particular job assigned by the employer and not to risk the safety of other co-workers. Pachman (Pachman, 2009) for example argue that this has not always been the case. Sometimes, "indiscriminate testing" is done with unwarranted results.

In Ghana, the Labour Act has no provision for the collection and use of medical information by employers on prospective employees for purposes of recruitment. The legal risk is that the whole structure of using a medical report to accept someone as an employee over the other amounts to discrimination in employment. Indeed, the Labour Act 651 of Ghana frowns on "restrictive conditions of employment". Section 14(e) (Labor Act, 2003a) specifically states that:

"An employer shall not in respect of any person seeking employment, or of persons already in his employment; discriminate against the person on grounds of gender, race, colour, ethnic origin, creed, social or economic status, disability or politics". The Act however makes provision for the protection of the worker with respect to occupational health, safety and environment. These provisions generally ensure that the employer maintains a safe working condition for the employee and minimizes hazards at the work place.

The above provision is premised on Article 17 of the 1992 Republican Constitution of Ghana which frowns on discrimination (Constitution of Ghana, 1992). The article is to the effect that, all persons shall be equal before the law. A person shall not be discriminated against on the grounds of gender, race, colour, ethnic origin, disability, creed or social or economic status. The Labour Act 651 
of Ghana defines a person with disability to mean "an individual who, on account of injury, disease or congenital deformity, is substantially handicapped in obtaining or keeping employment or in engaging in any work on his own or her own account, of a kind which apart from that injury, disease or deformity would be suited to his or her age, experience and qualification." However, the Labour Act 651, Section 59(1) (Labor Act, 2003b) stated that the employment of a young person (18 years but less than 21 years old) must be subject to medical fitness determined by a medical practitioner. The aim of this study is to evaluate the process of pre-employment medical report examinations-the law and the practice-in some public institutions in Kumasi.

\section{Methodology}

This study was conducted in two major public institutions in the Kumasi metropolis in Ghana. The identities of the institutions cannot be disclosed as most of the respondents want to remain anonymous. Three groups of respondents were used in the study. The sample for this study was $N=38 ; 20$ males and 18 females, respectively.

Group 1: Made up of employees who were employed within the past 5 years (Table 1). The reason we used this specific time period was to ensure that respondents could recall what happened before they were employed. Twenty people were purposely selected; ten males and ten females within the age range of twentyfive (25) and forty (40). Group 2: Made up of eight medical doctors who have been mandated to conduct and write medical reports of prospective employees (Table 2). Group 3: Made up of ten senior human resource staff members of the two public institutions examined (Table 3 ). Groups 2 and 3 were selected after they expressed interest to take part in the study. The respondents were all interviewed on specific questions directly related to the study. The data was de-coded and entered into excel for cleaning and editing. The data was finally exported into SPSS II (Chicago) for descriptive analysis.

\section{Results}

The sample for this study was $N=38$; made up of 20 males and 18 females. The average age was 34.4 years. Table 1 was made up of employees who were employed within the past 5 years. In Table 1 , it was evident that all prospective employee were subjected to medical examination. Table 2 represented the questions and responses of eight Medical doctors who have been mandated to conduct and write medical reports of prospective employees. Approximately $20 \%$ of employees believed it was acceptable for employers to know their medical status before they are employed, while a greater number (70\%) were indecisive according to Table 2. Table 3 was made up of ten senior human resource staff members of the two public institutions examined. The responses of the participants and the questions asked are as presented in the tables below.

\section{Discussion}

Most organizations expect less absenteeism in work, reduced medical bills and 
Table 1. Employee questions and responses.

\begin{tabular}{|c|c|c|c|}
\hline \multirow{2}{*}{$\begin{array}{c}\text { GROUP } 1 \\
\text { QUESTIONS }\end{array}$} & \multicolumn{3}{|c|}{ RESULTS (\%) } \\
\hline & Yes & No & Not sure \\
\hline Were you required to submit a medical report? & 100 & 0 & 0 \\
\hline Do you want your employer to know your medical status? & 20 & 10 & 70 \\
\hline Was the medical examination relevant to your job? & 35 & 5 & 60 \\
\hline Did the medical Doctor explain the content of medical report to you? & 5 & 95 & 0 \\
\hline Was the content of the examinations report sealed? & 90 & 10 & 0 \\
\hline Are you worried about your medical report becoming public knowledge? & 60 & 30 & 10 \\
\hline Do you think you will be denied employment if you do not submit a medical report? & 82 & 8 & 10 \\
\hline
\end{tabular}

Table 2. Medical doctor questions and responses.

\begin{tabular}{|c|c|c|c|}
\hline \multirow{2}{*}{$\begin{array}{c}\text { GROUP } 2 \\
\text { QUESTIONS }\end{array}$} & \multicolumn{3}{|c|}{ RESULTS (\%) } \\
\hline & Yes & No & Not sure \\
\hline Was the requested medical examination relevant to job description? & 15 & 8 & 77 \\
\hline Did you discuss the content of the medical report with the client? & 10 & 78 & 12 \\
\hline Is the request for medical report backed by law in Ghana? & 70 & 3 & 27 \\
\hline Did you know about the job description of client before writing the medical report? & 13 & 65 & 22 \\
\hline
\end{tabular}

Table 3. Human resource staff questions and responses.

\begin{tabular}{|c|c|c|c|}
\hline \multirow{2}{*}{$\begin{array}{c}\text { GROUP } 3 \\
\text { QUESTIONS }\end{array}$} & \multicolumn{3}{|c|}{ RESULTS (\%) } \\
\hline & YES & No & Not sure \\
\hline Is medical fitness the reason for the request? & 100 & 0 & 0 \\
\hline Is the Request of pre-employment supported by law? & 85 & 0 & 15 \\
\hline Do prospective employees still get employed if they don't submit medical report? & 6 & 74 & 20 \\
\hline Do you have a medical review board to review the medical reports of prospective employees? & 0 & 15 & 85 \\
\hline Do you keep the medical reports of employees on their identifiable personal files? & 100 & 0 & 0 \\
\hline Can other Human Resource staff have access to the medical reports of employees? & 75 & 2 & 23 \\
\hline
\end{tabular}

maximum efficacy from their employees. The only way to ensure this is to employ people who are medically fit to work. From this study, it was evident that all the employees were asked to submit a medical report together with their acceptance letter before they could start work. This practice is not in line with the Labour Act, 2003 and the 1992 Constitution of Ghana. In fact, the above laws frown on mandatory pre-employment medical examination as it can be the basis of unfair treatment of prospective employees. The objective of pre-employment examinations has traditionally been to ensure that prospective employees can perform their jobs safely without placing co-workers at risk. Despite these focused goals, pre-employment testing sometimes exceeds this scope (Harris et al., 2004). Indiscriminate testing inevitably yields findings that are not relevant to the job description of the prospective employee (Whysner et al., 2003). An ex- 
ample of a long-established occupational health practice that has recently undergone careful analysis is the pre-employment chest X-ray. Loyhiya et al. (Lohiya et al., 2006) undertook an empirical analysis of the efficacy of this practice. They concluded that the use of the chest X-ray as a pre-employment requirement was contrary to established practice guidelines, unnecessary and wasteful (Lohiya et al., 2006).

This research has indicated that approximately $20 \%$ believe it is acceptable for employers to know their medical status before they are employed, while a greater number $(70 \%)$ were indecisive. This implies that most prospective employees are not conversant with laws that govern employment. This may be the reason why a majority of the individuals sampled could not tell whether the medical examination requested was relevant to the job sought.

Another worrying situation in practice was that, in this current study, an over-whelming majority (95\%) of respondents indicated that the content of the medical report was not discussed with them by the examining doctor. Ninety percent (90\%) of respondents advised the medical report was subsequently presented to them in a sealed envelope for submission to their prospective employer. Doctors have a responsibility to discuss the content of the medical report with their clients before they are finally forwarded to the human resource department. One of the ways doctors can reduce their risk in the area of legal suit is to establish with prospective employers and employees the ground rules when conducting medical fitness to work examinations (Lee \& Koh, 2008). Again, the majority (82\%) in Group 1 (employees) maintained the view they would be denied employment if they did not submit the medical report to the prospective employer. Thus, while prospective employees (60\%) presented a report (whose contents they are mostly unaware of) about their personal medical conditions in a sealed envelope, they were against its disclosure to their prospective employer. This assertion was based on the belief that without the report they could not be employed. This practice, in our view, can result in discrimination and likely violates the human rights of prospective employees.

The doctors who conducted medical examinations in this study indicated that in a majority of situations the examination requested by the employer is not relevant. The laws of Ghana do not require these doctors to be occupational health physicians. Even though not included in the questionnaire, the majority of doctors in this study are of the opinion that the same general medical examination requested for all categories of staff is not a fair practice. Over $70 \%$ of the doctors believe that a pre-employment medication examination is supported by law. Most doctors (78\%) admitted not discussing the content of the report with their clients. Additionally, sixty-five (65\%) admitted not always being aware of the job description of their client. The goal of the pre-employment examination is to determine whether an individual is fit to perform his or her job without risk to himself or others. This is also conceptualized within the practice of occupational medicine-it is assumed that the examiner is required to have detailed knowledge of both working and health conditions (Serra et al., 2007). 
Empirically, the authors could state that the decision to declare the fitness level of a prospective employee is not solely based on the job requirement of the client, but rather on their general physical fitness. The authors of this study assert the fact that an individual has uncontrolled hepatitis B, for example does, not assume an individual cannot perform the functions of an accountant, as opposed to someone working as a surgeon.

Among the human resource personnel who participated in this study, all $(100 \%)$ indicated that the reason why prospective employers requested a potential employee to undergo a pre-employment medical examination was to determine their fitness to work. Studies have shown that this practice can be used by employers to discriminate against applicants on racial, political, and disability bases. A typical example is a study conducted by Murphy (Murphy, 1992) which illustrates that African Americans are at a higher risk for higher blood pressure and hypertension.

Murphy conducted a survey to determine whether occupational physicians exclude job applicants by applying blood pressure criteria (Murphy, 1992). Sixty eight percent of the physicians reported excluding job applicants with hypertension permanently, on their own initiative. The author also noted that "the high prevalence of hypertension in the adult population ensures that its widespread use as a criterion for employment would have significant social implications". Murphy thus concluded that there is a need for consensus on appropriate guidelines to preclude inappropriate discrimination against hypertensive job applicants (Murphy, 1992). In this current study it was clear that most of the human resource personnel (85\%) believe the request is supported by law. Again, the majority (74\%) indicated that, without the medical report, prospective employees cannot be employed. According to Serra C. (Serra et al., 2007), there is confusion about the current methodology of assessing general fitness for work. Serra (Serra et al., 2007) also concluded that empirical data related to fitness to work decisions is scarce. We believe this is due in part to a lack of standard or valid methodologies for all professions and circumstances. We posit that this practice is therefore a clear violation of established laws and lends itself to possible human rights issue. It was also indicated that medical reports of employees are kept on employers personal files without any de-identifier. This means that any member of the Human Resource Unit could have access to the medical records of an employee. This is violation of employee's medical confidentiality which is fundamental as indicated in the Patients' Rights Charter of the Ghana Health Services.

\section{Conclusion}

From the above analysis of the law, it was evident that there is no law in Ghana which supports mandatory pre-employment medical examinations of prospective employees. In fact, it was found that most of the international laws from developed countries do not support this practice.

It can be concluded that based on the above laws that there is no legal basis for 
the mandatory request of medical examination reports of prospective employees. However, the laws have provisions for this practice, particularly if the job poses some inherent risk to ensure that the working environment is safe. It can also be concluded that medical reports do not always take into consideration the job description of the prospective employee. We assert that reliance on the medical report to determine the fitness of a prospective employee for a particular job is not based on fair evaluation and is thus unjustifiable; at least in the studied institutions. Finally, most of the medical practitioners who conduct the medical examinations are not occupational health doctors trained to do examinations related to the demands of the work.

\section{Recommendations}

The authors support the idea behind the indiscriminate demand of pre-employment medical reports of prospective employees. However, there should be proper legislation to support the practice and it should be done in accordance with the laws of Ghana. Also, the examination, where necessary, should be tailored to the job description and the working environment. Again, medical reports should be submitted to the medical board of choice of the employer and the identity of the individual should be protected as demanded by the Data Protection Act 2012, Act 843 of Ghana.

\section{References}

(1992). Constitution of Ghana. Article 17

(1998). Employment Equity Act, 55 of 1998, South Africa. Act 55.

(2003a). Labour Act 651 Section 14 (E). Ghana.

(2003b). Labour Act 651 Section 59(1). Act 651. Ghana.

California Gov't Code 12940(e-F)). California's Fair Housing and Employment Act.

Cox, R. A. F., Edwards, F. C., \& Palmer, K. (2009). Fitness for Work: The Medical Aspects (3rd ed.). New York: Oxford Medical Publications.

Harris, J. S., Glass, L. S., Mueller, K. L., Genovese, E., \& ACOEM Practice Guidelines Committee (2004). Evidence-Based Clinical Occupational Medicine: Updating the ACOEM Occupational Medicine Practice Guidelines. Clinics in Occupational and Environmental Medicine, 4, No. 2. https://doi.org/10.1016/j.coem.2004.02.002

Lee, S. M., \& Koh, D. (2008). Fitness to Work: Legal Pitfalls. Annals of the Academy of Medicine, Singapore, 37, 236-240.

Lohiya, G.-S., Tan-Figueroa, L., Lohiya, P., \& Bui, D. (2006). The Futility of Universal Pre-Employment Chest Radiographs. Journal of the National Medical Association, 98, 2019-2023.

Luck v. Southern Pacific Transportation Co. (1990). Court of Appeals of California, First Appellate District, and Division Four.

Murphy, M. B. (1992). Blood Pressure and Fitness for Work. American Journal of Hypertension, 5, 253-256.

Pachman, J. (2009). Evidence Base for Pre-Employment Medical Screening. Bulletin of the World Health Organization, 87, 529-534. https://doi.org/10.2471/BLT.08.052605

Serra, C., Rodriguez, M. C., Delclos, G. L., Plana, M., Gómez López, L. I., \& Benavides, F. 
G. (2007). Criteria and Methods Used for the Assessment of Fitness for Work: A Systematic Review. Occupational and Environmental Medicine, 64, 304-312.

https://doi.org/10.1136/oem.2006.029397

Whysner, J. A., \& Chase, K. H. (2003). Risk Assessment in the Workplace. Philadelphia, PA: Lippincott, Williams and Wilkins.

Submit or recommend next manuscript to SCIRP and we will provide best service for you:

Accepting pre-submission inquiries through Email, Facebook, LinkedIn, Twitter, etc. A wide selection of journals (inclusive of 9 subjects, more than 200 journals)

Providing 24-hour high-quality service

User-friendly online submission system

Fair and swift peer-review system

Efficient typesetting and proofreading procedure

Display of the result of downloads and visits, as well as the number of cited articles Maximum dissemination of your research work

Submit your manuscript at: http://papersubmission.scirp.org/

Or contact blr@scirp.org 